Direitos Humanos e Democracia - Mariana Baggio Annibelli

\title{
A ORDEM ECONÔMICA BRASILEIRA E O COOPERATIVISMO
}

\author{
Mariana Baggio Annibelli*
}

\begin{abstract}
RESUMO
O presente artigo visa ressaltar a importância do cooperativismo dentro da Ordem Econômica brasileira, fundada na Constituição Federal de 1988, como mecanismo para que se atinja o bem estar econômico e social da população, visando garantir, assim, existência digna a todos, propiciando, desta forma, que se cumpram os princípios fundamentais da República, tendo em vista o potencial emancipatório do cooperativismo, pois serve como instrumento de inclusão, de resgate da cidadania e, portanto, de desenvolvimento, vindo as suprir as deficiências do Estado e do mercado, que cada vez mais têm se demonstrado incapazes de corrigirem certas distorções criadas pelo capitalismo. No Brasil são quase oito milhões de cooperados, reunidos em treze setores diferentes, que se beneficiam desse sistema, mas que poderiam ser mais, caso houvesse evolução da legislação nacional correspondente, adaptando-se aos novos parâmetros econômicos mundiais e nacionais, deixando de lado a ótica conservadora que norteou a legislação cooperativista brasileira de 1971, visando, desta forma, compensar e corrigir certas desarticulações sociais e econômicas existentes.
\end{abstract}

Palavras-chave: cooperativismo, ordem econômica brasileira, inclusão social.

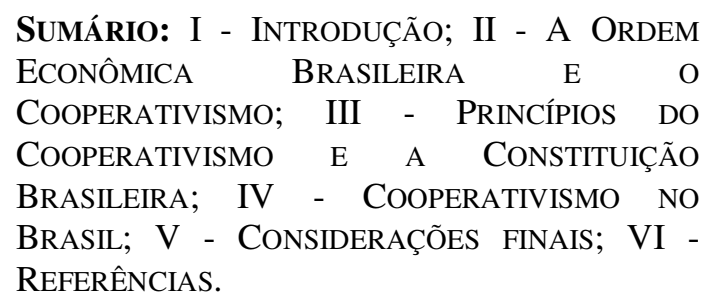

\section{I - INTRODUÇÃO}

O objetivo do presente estudo é o de ressaltar a importância do cooperativismo

* Advogada e Geógrafa, Mestranda em Direito Econômico e Socioambiental da PUC/PR. Bolsista Capes. mariannibelli@yahoo.com.br. 
dentro da Ordem Econômica brasileira, fundada na Constituição Federal de 1988, como mecanismo para que se atinja, acima de tudo, o bem-estar econômico e social da população, visando garantir, assim, uma existência digna a todos. O cooperativismo pode ser considerado como instrumento econômico e social, com suporte constitucional, que propicia que se atinjam os princípios fundamentais da República, haja vista seu potencial emancipatório, pois serve como instrumento de inclusão, de resgate da cidadania e, portanto, de desenvolvimento.

Parte-se do pressuposto da Ordem Econômica como conjunto de normas jurídicas e sociais que pautam as relações humanas e afetam a economia. Considera-se, porém, que a ordem econômica não se esgota na Constituição econômica, tanto em virtude de seu caráter programático, como também porque se apresentam como matriz constitucional, ou seja, como normas muito gerais. Adota-se, portanto, como base legal também legislação infraconstitucional correspondente.

Considera-se cooperativismo, de acordo com o artigo $4^{\circ}$ da Lei $5.764^{1}$ de 1971, como sendo "sociedades de pessoas, com forma e natureza jurídica próprias, de natureza civil, não sujeitas à falência, constituídas para prestar serviços aos associados, distinguindo-se das demais sociedades pelas suas características próprias".

Para a Aliança Cooperativa Internacional, cooperativismo é uma associação autônoma de pessoas, que se uniram de forma voluntária para satisfazer suas necessidades e aspirações econômicas, sociais e culturais em comum, mediante uma empresa de sociedade conjunta e de gestão democrática.

As cooperativas estão alicerçadas em princípios e valores, dentre eles a solidariedade, a democracia, a ajuda mútua, a responsabilidade com o próximo e a igualdade, que contribuem para um futuro social e econômico mais seguro, ressaltando os valores éticos de honestidade, franqueza, responsabilidade social e cuidado com o próximo, conforme a análise que se observa a seguir.

\footnotetext{
${ }^{1}$ A Lei 5.764, de 16 de dezembro de 1971, define a Política Nacional de Cooperativismo, institui o regime jurídico das sociedades cooperativas, e dá outras providências.
} 
A ORdEM ECONÔMICA BRASILEIRA E O COOPERATIVISMO

\section{II - A ORDEM ECONÔMICA BRASILEIRA E O COOPERATIVISMO}

A Constituição Federal trata da atividade econômica e de suas implicações decorrentes em diferentes partes. Já em seu artigo $1^{\circ}$ define como fundamento do Estado Democrático de Direito: II - a cidadania; III - a dignidade da pessoa humana; e os IV - valores sociais do trabalho e da livre iniciativa, como direitos que devem ser tutelados pelo Estado, buscados e alcançados pelos cidadãos. Para tanto, em seu artigo

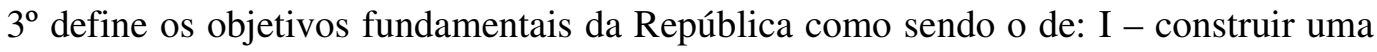
sociedade livre, justa e solidária; II - garantir o desenvolvimento nacional; III erradicar a pobreza e a marginalização e reduzir as desigualdades sociais e regionais; IV - promover o bem de todos, sem preconceitos de origem, raça, sexo, cor, idade e quaisquer outras formas de discriminação. Cabe, portanto, ao Estado criar condições favoráveis para que tais objetivos sejam alcançados.

Sendo assim, de acordo com o artigo 21 da Constituição, compete à União, dentre outras atribuições: IX - elaborar e executar planos nacionais e regionais de ordenação do território e de desenvolvimento econômico e social. Nestes planos deverão estar contidos mecanismos para que se alcancem os objetivos fundamentais da República. Observa-se, porém, que tanto o desenvolvimento econômico, quanto o social, devem ser buscados. De nada serve alcançar o desenvolvimento econômico, se com ele não vier o desenvolvimento social, garantindo, assim, com efetividade, o cumprimento dos demais preceitos constitucionais, que competem ao Estado do bemestar social (well fare state).

Para Pierre Rosanvallon, o Estado moderno pensado entre os séculos XIV e XVIII por Locke e Hobbes se definiu como Estado protetor, baseado na produção da segurança e redução das incertezas. Não existe Estado protetor sem indivíduo que possua direitos e vice-versa. Ambos estão assegurados pelo contrato social. O primeiro direito estabelecido foi o direito à vida, sendo obrigação do Estado produzir a paz civil. A propriedade é tida como prolongamento, atributo indissociável do indivíduo, que o defende e o protege, ao mesmo tempo. Sendo assim, "indivíduo - propriedade - 
Estado protetor" são inseparáveis. E, portanto, o Estado moderno só pode ser concebido com base no Estado protetor. Porém, o Estado protetor é muito mais que o moderno, pois além de assegurar direitos (vida e propriedade), também leva a cabo ações afirmativas (de redistribuição de renda, de regulamentação das relações sociais, de implementação de serviços coletivos). Na verdade, o Estado-providência é uma radicalização e uma correção do Estado Moderno, em virtude dos movimentos de liberdade e igualdade do século XVIII ${ }^{2}$.

Desta forma, os direitos econômicos e sociais aparecem como um prolongamento dos direito civis, garantindo aos quase-proprietários os mesmos direitos e seguranças materiais e físicas daqueles que são proprietários. O movimento democrático propôs-se a estender esses direitos (civis, políticos, sociais e econômicos) a todos os cidadãos. Sendo assim, a evolução do Estado protetor ao Estado providência corresponde à necessidade de corrigir e compensar certa desarticulação social.

De acordo com o artigo 170 da Constituição, à ordem econômica, fundada na valorização do trabalho humano e na livre iniciativa, com finalidade de assegurar a todos existência digna, conforme os ditames de justiça social, cabe observar, dentre outros princípios, o da: VII - redução das desigualdades regionais e sociais. As desigualdades regionais e sociais poderão reduzidas, gradativamente, por meio de ações afirmativas do Estado, de distribuição de renda, que visem integrar pessoas consideradas excluídas do sistema moderno vigente, disponibilizando-lhes mecanismos que possibilitem o processo emancipatório almejado, especialmente quanto à educação, formação e ao acesso à informação, dotando-lhes de capacidade de autonomia de escolha, tornando-os capazes de interagirem e participarem social e economicamente das ações e decisões que lhes dizem respeito.

Estabelece-se, desta forma, no artigo 174 da Constituição, que o Estado, como agente normativo e regulador da atividade econômica, exercerá as funções de fiscalização, incentivo e planejamento, determinante para o setor público e indicativo

\footnotetext{
${ }^{2}$ ROSANVALLON, Pierre. La crisis del Estado Providencia. Madrid: Civitas, 1995.
} 


\section{A ORDEM ECONÔMICA BRASILEIRA E O COOPERATIVISMO}

para o setor privado. Em seu $\S 2^{\circ}$, enfatiza que a lei apoiará e estimulará o cooperativismo e outras formas de associativismo, justamente por reconhecer nele a possibilidade de emancipação sócio-econômica de seus cooperados. Tanto é fato que a própria Constituição Federal assegura em cláusula pétrea, portanto, imutável, em seu artigo $5^{\circ}$, XVIII, que a criação de associações e de cooperativas independem de autorização, sendo vedada a interferência estatal em seu funcionamento.

Ressalta-se, para tanto, que a ordem econômica brasileira refuta claramente o socialismo, uma vez que um dos pilares do Estado nacional é a propriedade privada. Rejeita, também, o modelo capitalista puro, optando pela social democracia capitalista.

Dentro desta perspectiva que se insere, o cooperativismo merece extremo destaque e atenção, em que pese tenha sido considerado por teóricos como a terceira força econômica ${ }^{3}$, localizado entre o capitalismo e o socialismo, possui, de fato, como finalidade o desenvolvimento econômico e social de seus cooperados, embasado por um conjunto de valores e princípios, destacando-se: a solidariedade, a democracia e a igualdade, visando assegurar um futuro econômico mais seguro ${ }^{4}$. Ademais, ao elevar o padrão de vida de seus cooperados, beneficia, ao mesmo tempo, a sociedade em geral, devido ao aumento da produção gerado e, em consequiência, ao barateamento dos preços dos bens produzidos, favorecendo o aumento do consumo e a disponibilidade de crédito.

Cooperativas podem ser consideradas alternativas autênticas às falhas dos mercados e dos governos, ajudando a oferecer estrutura e participação às pessoas, quer seja por meio de acesso ao crédito, aos produtos de consumo, de estabilidade econômica mediante um emprego seguro, a uma moradia acessível ou à satisfação de múltiplas necessidades, de acordo com a modalidade de cada cooperativa.

${ }^{3}$ NORONHA, Adolfo Vasconcelos. Cooperativismo. [S.1.]: Cupolo, 1976, p. 15.

${ }^{4}$ Conforme propõe a Aliança Cooperativa Internacional (ACI), cujo objetivo é "construir a paz através das cooperativas". A ACI é uma organização não governamental independente que reúne, representa e serve às organizações cooperativas de todo o mundo. Fundada em 1895, possui 224 membros formados por cooperativas nacionais e internacionais, de 91 países. No total representam aproximadamente 800 milhões de pessoas. Informações constantes em: http://www.ica.coop/activities/idc/2006-idc-sp.pdf. Acesso em 7 de dezembro de 2007. 
As empresas de capital são úteis porque geram empregos e estimulam a economia. Emprego significa sobrevivência. Sobrevivência é um conceito restrito porque significa apenas continuar a viver. Para o homem não basta sobreviver porque como ser superior ele precisa se realizar, ou seja, fazer, construir, criar, alcançar ideais e sentir que seu trabalho e sua profissão contribuem para o bem-estar da sociedade. Mais que sobrevivência, a cooperativa garante ao homem a sua realização 5 .

Desta forma abrem-se caminhos de inclusão, ao invés da lógica capitalista neoliberal excludente $^{6}$, oferecendo às pessoas capacidades de ajuda mútua, contribuindo, ainda, a eliminar muitas das condições que podem acabar em conflito, dentro da própria comunidade, ou entre elas, contribuindo, assim, para a existência de vida digna e pacífica.

\section{III - PRINCÍPIOS DO COOPERATIVISMO E A CONSTITUIÇÃo BRASILEIRA}

Os princípios cooperativos são as premissas com as quais as cooperativas colocam em prática seus valores de ajuda mútua, auto-responsabilidade, democracia,

\footnotetext{
${ }^{5}$ IRION, João Eduardo. Cooperativismo e economia social. São Paulo: STS, 1997, p. 11.
}

6 "No domínio da globalização neoliberal, a idéia é a de que a estabilidade econômica dos Estados e o seu crescimento baseiam-se na redução dos custos salariais. Assim, é necessário, segundo nos informa Boaventura de Souza Santos (in A globalização e as ciências sociais. São Paulo: Cortez, 2002) proibir a indexação dos salários, flexibilizar os direitos laborais, liberalizando o mercado de trabalho e, supostamente, impedindo o impacto inflacionário dos aumentos salariais. A busca de mercados externos vai suprir a perda de poder de compra interno em função das ditas medidas. Assim, se dessocializa as medidas e o conceito de consumidor passa a ser o de cidadão (...). Reforçando este entendimento Capella (in Fruta proibida: uma aproximación historico-teoretica al estudio del derecho y del Estado. Madrid: Trotta, 1997) acrescenta que a mundialização desigual, cujos principais agentes, no seu entender, são as grandes empresas transnacionais e a terceira revolução industrial, operam uma grande transformação nas condições do mundo do trabalho, com a redução do espaço social ocupado pelos trabalhadores. Se o capitalismo concorrencial, através das revoluções industriais anteriores, incorporava cada vez mais pessoas ao trabalho assalariado, liquidando o trabalho artesanal e inflando os centros fabris urbanos de pessoas, a terceira revolução, ao combinar a nova tecnologia informática com políticas de desregulamentação do trabalho, permite ao capital substituir um número cada vez maior de trabalhadores por máquinas automáticas. O empresariado dispensa uma parte cada vez maior da mão-de-obra e endurece as condições laborais de quem permanece empregado". ROSSI, Amélia do Carmo Sampaio. Cooperativismo à luz dos princípios constitucionais. Curitiba: Juruá, 2005, p. 64-65. 


\section{A ORdEM ECONÔMICA BRASILEIRA E O COOPERATIVISMO}

igualdade, eqüidade e solidariedade. São sete os princípios cooperativos, quais sejam: de adesão voluntária e aberta; de gestão democrática por parte dos sócios; de participação econômica dos sócios; de autonomia e independência; de educação, formação e informação; de cooperação entre cooperativas; e o de interesse pela comunidade ${ }^{7}$.

Com base nos princípios elencados, há que se considerar que: entre os sócios não pode haver discriminação, que seja social, política, religiosa, racial ou de sexo; todos os sócios têm direitos iguais quanto aos votos (um sócio, um voto), assim como as cooperativas, ao cooperarem, também estão organizadas da mesma forma democrática (uma cooperativa, um voto); os sócios contribuem eqüitativamente ao capital de suas cooperativas e as gerem de forma democrática; as cooperativas, justamente pelo fato de serem autônomas e de ajuda mútua, podem firmar acordo com outras organizações, inclusive governos; as cooperativas proporcionam educação e formação aos seus cooperados, aos seus representantes eleitos, aos seus diretores e aos seus empregados, para que possam contribuir de forma eficaz ao desenvolvimento de suas cooperativas, devendo, ainda, informar e divulgar ao grande público os benefícios da cooperação; devem, portanto, servir aos seus cooperados de forma mais eficaz possível, visando fortalecer o movimento cooperativo, trabalhando conjuntamente em âmbito local, regional, nacional e internacional; as cooperativas, desta forma, trabalham para alcançar o desenvolvimento sustentável de suas comunidades, mediante políticas aprovadas por seus cooperados.

É possível verificar, ao analisarem-se os princípios cooperativos acima elencados, à luz da Constituição brasileira de 1988, que há uma sintonia entre os eles e os valores fundamentais do Estado Democrático brasileiro, tais como de liberdade, igualdade, democracia, dignidade da pessoa humana, justiça social ${ }^{8}$.

7 Declaração sobre a Identidade Cooperativa, da Aliança Cooperativa Internacional. Constante em: http://www.ica.coop/coop/principles/coopidentitylanguages.pdf. Acesso em 7 de dezembro de 2007.

${ }^{8}$ ROSSI, op. cit., p. 136. 


\section{IV - COOPERATIVISMO NO BRASIL}

Em que pese o Cooperativismo ter surgido na aldeia de Rochdale, Inglaterra, em 1844, por meio de uma cooperativa de consumo, idealizada por seu precursor, Robert Owen, as primeiras experiências do cooperativismo brasileiro remontam ao final do século XIX, ou seja, cinqüenta e três anos depois, com a criação da Associação Cooperativa dos Empregados, em 1891, na cidade de Limeira-SP, e da Cooperativa de Consumo de Camaragibe - Estado de Pernambuco, em 1894. A partir de 1902, surgem as primeiras experiências das caixas rurais do modelo Raiffeisen, no Rio Grande do Sul e, em 1907, são criadas as primeiras cooperativas agropecuárias no Estado de Minas Gerais 9 .

Atualmente, o cooperativismo brasileiro é amparado pela Lei n. $5.764^{10}$, de 16 de dezembro de 1971, que exige um número mínimo de vinte sócios para a sua constituição e é representado, formalmente, pela Organização das Cooperativas Brasileiras (OCB) em nível nacional e da Organização Estadual de Cooperativas $(\mathrm{OCE})^{11}$, em nível de cada Unidade da Federação.

${ }^{9}$ SILVA, Emanuel Sampaio et all. Panorama do cooperativismo brasileiro: história, cenários e tendências. Revista UniRcoop, v.1 \#2, p. 78, 2003.

10 "Há controvérsias sobre a vigência de alguns artigos da Lei n5.764, de 1971, que instituiu o regime jurídico das cooperativas. Alguns doutrinadores entendem que o Código Civil de 2002, ao tratar das cooperativas nos arts. 1.093 a 1.096, teria revogado parcialmente a Lei n 5.764/1971 (Fiúza, 2004). Isso porque a Lei de Introdução ao Código Civil (Decreto-Lei $n^{\circ} 4.657$, de 1942) estabelece que, quando uma lei nova dispõe sobre matéria incompatível com lei anterior, esta é revogada (total ou parcialmente) por aquela. Por outro lado, a LICC determina que lei geral mais nova que disponha sobre aspectos gerais ou especiais, além dos já existentes, não revoga nem modifica lei anterior. $\mathrm{O}$ desafio é investigar se, de fato, o art. 1.094, inciso II, do novo Código Civil, que trata do concurso do número mínimo de sócios, teria revogado o art. $6^{\circ}$ da Lei das Cooperativas, que exige o mínimo de vinte sócios para constituição de cooperativas. Prevalecendo este entendimento, a exigência que vige hoje é menos restritiva, pois o texto do Código Civil estabelece a regra de que é necessário apenas o número mínimo de sócios necessário para compor a administração. Por seu texto, portanto, e contrariamente à lei de 1971, é permissível que o número de sócios seja menos de vinte". BETÃO, Deputado Reinaldo. Relatório da Comissão de Desenvolvimento Econômico, Indústria e Comércio. Projeto de Lei no3.767/ 2004. Disponível em http://www.camara.gov.br/sileg/integras/257011.pdf. Acesso em 8 dez. 2007.

${ }^{11}$ Com exceção ao Estado do Paraná onde a Organização das Cooperativas Estaduais chamase OCEPAR, ao invés de OCE, como ocorre em todos os outros Estados nacionais. 


\section{A ORDEM ECONÔMICA BRASILEIRA E O COOPERATIVISMO}

Tanto a lei específica sobre o cooperativismo de 1971 quanto a criação da OCB em 1969 ainda que tenham permitido uma maior definição das especificidades das cooperativas no Brasil, representaram forte ingerência do Estado no funcionamento destas organizações. Há de se salientar, nesse sentido, que o panorama político-institucional do momento era de ditadura militar. (...) Porém, desde a aprovação da Constituição de 1988, a prática cooperativa se desvincula do Estado e vários projetos de lei passam a tramitar pelo Congresso Nacional com o propósito de alterar a Lei 5.764/713. Pretende-se, com isso, ampliar as margens de ação diante de um mercado globalizado e diminuir "brechas legais", de forma a inibir práticas fraudulentas das chamadas "cooperativas de fachada" ${ }^{12}$.

A discussão atual tanto nas universidades quanto nos órgãos de representação do cooperativismo, refere-se ao esforço de revitalização das práticas cooperativas, inseridas dentro de um movimento mais amplo de modernização das atividades e de ampliação da democracia, ganhando ressonância com as discussões sobre economia solidária e terceiro setor. Esta nova perspectiva se distancia daquela observada na década de 80, quando a literatura serviu para denunciar que o movimento cooperativista do país se inseria dentro de diretrizes de uma "modernização conservadora", em que o Estado atuava de forma autoritária e centralizada. De acordo com diversos autores, esse modelo de modernização veio a favorecer médios e grandes agricultores voltados à cultura de exportação, em detrimento de uma agricultura de subsistência desenvolvida pela agricultura de base familiar. Infelizmente, o modelo adotado no Brasil, à semelhança de outras experiências na América Latina, utilizou-se do cooperativismo como instrumento de controle social e político, diferentemente da Europa, onde o cooperativismo surge como uma forma de organização proletária. No Brasil, ao contrário, representa a promoção das elites políticas e agrárias ${ }^{13}$.

Mesmo que as práticas cooperativas brasileiras ainda expressem algumas discrepâncias - resultado de um modelo implementado de cima para baixo, desvinculado das necessidades de amplos segmentos sociais - observa-se que o cooperativismo, enquanto idéia força, está ganhando amplitude através de uma perspectiva positiva - sinalizando seu caráter de inclusão social - e não mais negativa

\footnotetext{
${ }^{12}$ SILVA, op. cit., p. 79.

${ }^{13}$ Idem.
} 
Revista Eletrônica do CEJUR, Curitiba-PR, a. 2, v. 1, n. 3, ago./dez. 2008

pelo seu caráter excludente (que foi a ótica do passado).

Cinco fatores, especialmente - de ordem interna e externa ao país - parecem contribuir para essa mudança de enfoque:

a) a revitalização dos conceitos e da prática cooperativa a partir de um balanço em relação às práticas do passado;

b) o crescimento do desemprego estrutural, estimulando a proliferação de organizações de economia solidária;

c) o caráter competitivo da globalização que impõe práticas cooperativas com boa performance empresarial;

d) a flexibilização das relações de trabalho, estimulando práticas autogeridas;

$\mathrm{e}$

e) a ampliação das discussões em torno dos conceitos de desenvolvimento local e de idéia de economia social e terceiro setor ${ }^{14}$.

Tais afirmações se verificam nos dados recentes divulgados pela Organização das Cooperativas Brasileiras (OCB): o cooperativismo brasileiro é hoje uma importante força econômica no País, composto por 7.672 cooperativas singulares dos diversos ramos, com 7.687.568 de cooperados, gerando de forma direta 250.961 empregos. As cooperativas são responsáveis por um volume de transações econômicas equivalente a 6\% PIB (Produto Interno Bruto). O sistema cooperativista é composto por treze ramos, de acordo com as especificidades das respectivas atividades econômicas. O ramo mais forte em termos de faturamento é o agropecuário. Em número de cooperativas é a do trabalho e, em número de cooperados, é a do ramo de crédito que se destaca, conforme se observa na tabela 1, a seguir:

\footnotetext{
${ }^{14}$ Ibidem, p. 80.
} 
A ORdEM ECONÔMICA BRASILEIRA E O COOPERATIVISMO

\section{TABELA 1: NÚMEROS DO COOPERATIVISMO POR RAMO DE ATIVIDADE} (31/DEZ/2007)

$\begin{array}{llll}\text { Ramo } & \text { Cooperativas } & \text { Cooperados } & \text { Empregados } \\ \text { Agropecuário } & 1.544 & 879.649 & 139.608 \\ \text { Consumo } & 141 & 2.468 .293 & 8.984 \\ \text { Crédito } & 1.148 & 2.851 .426 & 37.266 \\ \text { Educacional } & 337 & 62.152 & 2.913 \\ \text { Especial } & 12 & 385 & 13 \\ \text { Habitacional } & 381 & 98.599 & 1.258 \\ \text { Infra-estrutura } & 147 & 627.523 & 5.867 \\ \text { Mineral } & 40 & 17.402 & 77 \\ \text { Produção } & 208 & 11.553 & 1.427 \\ \text { Saúde } & 919 & 245.820 & 41.464 \\ \text { Trabalho } & 1.826 & 335.286 & 6.682 \\ \text { Transporte } & 945 & 88.386 & 5.363 \\ \text { Turismo e lazer } & 24 & 1.094 & 39 \\ \text { Totais } & \mathbf{7 . 6 7 2} & \mathbf{7 . 6 8 7 . 5 6 8} & \mathbf{2 5 0 . 9 6 1}\end{array}$

Fonte: OCE's e OCB, 2007.

Conforme se verifica na tabela 1, portanto, as cooperativas de trabalho correspondem a $24 \%$ do total no país, enquanto que as relacionadas ao setor agropecuário equivalem a $20 \%$ do total, em terceiro lugar estão as cooperativas de crédito, correspondendo a $15 \%$ e, $\log$ em seguida, ambas com $12 \%$ vêm as de transporte e as de saúde. As cooperativas de educação correspondem a 4\% do total, as de consumo $3 \%$ e as de infra-estrutura a $2 \%$.

Conforme dados da OCB, é nas regiões sudeste, nordeste e sul onde está concentrada a maior parte das cooperativas brasileiras, correspondendo a $80 \%$ do total. No sudeste encontra-se $41 \%$ do total das cooperativas nacionais, enquanto que no nordeste $20 \%$ e na região sul 19\%. Logo em seguida está a região norte com $11 \%$ e, com a menor concentração de cooperativas, com apenas $9 \%$ do total, vem a região centro-oeste.

De acordo com a $\mathrm{OCB}$, inúmeros benefícios são gerados pelo sistema cooperativista aos seus cooperados. No setor agropecuário, por exemplo, estima-se que 
o benefício tenha sido de algo em torno a 28.330 bilhões de reais, revertidos em prol dos cooperados que, caso não o fossem pagariam mais por assistência técnica e serviços especializados, pagariam também preços mais elevados por insumos e serviços e receberiam menor preço em seus produtos, transferindo boa parte de sua margem de lucro às multinacionais.

Da mesma forma ocorre com as cooperativas de crédito, de acordo com dados da $\mathrm{OCB} / 2007$, as cooperativas de crédito geraram um diferencial de renda para os associados de 154 milhões de reais ao mês, estimando-se algo em torno de 1.840 bilhão de reais ao ano. Recursos esses que se destinam ao consumo e que promovem a circulação de mercadorias no comércio local, assim como com as cooperativas de saúde. Estima-se que as cooperativas de saúde geraram um diferencial de renda de 520 milhões de reais para os seus cooperados no ano de 2007.

\section{V - CONSIDERAÇÕES FINAIS}

Diante do exposto, há que se considerar que o cooperativismo, em face da realidade econômica mundial e nacional, pode ser encarado como mecanismo de inclusão social e desenvolvimento, estando amparado pela ordem econômica brasileira vigente, vindo as suprir as deficiências do Estado e do mercado, que cada vez mais têm se demonstrado incapazes de corrigirem certas distorções criadas pelo capitalismo neoliberal globalizado, principalmente acerca da distribuição de renda e desemprego, desenvolvendo e propondo atividades alternativas aos associados e familiares, podendo proporcionar-lhes rendas adicionais, além de qualificação profissional voltadas às necessidades do cooperado e do mercado.

Faz-se necessário, porém, que se adapte a legislação nacional à nova realidade econômica mundial, deixando de lado a ótica conservadora que norteou a legislação cooperativista nacional de 1971 (que exige no mínimo vinte sócios para que se crie uma cooperativa), revisando conceitos em face da prática cooperativista, estimulando a 


\section{A ORDEM ECONÔMICA BRASILEIRA E O COOPERATIVISMO}

criação de novas cooperativas, de economia solidária, onde seja possível um número mínimo menor de cooperados.

Trata-se, portanto, de cumprir as previsões constitucionais, aumentando as possibilidades de se compensar e corrigir certas desarticulações sociais e econômicas, que vêm se perpetuando ao longo dos últimos cinco séculos, promovendo, ainda, a utilização mais eficiente dos recursos naturais e apoiando as iniciativas voltadas ao desenvolvimento local, satisfazendo as necessidades e aspirações econômicas, sociais e culturais dos cooperados.

\section{VI - REFERÊNCIAS}

BETÃO, Deputado Reinaldo. Relatório da Comissão de Desenvolvimento Econômico, Indústria e Comércio. Projeto de Lei $n^{o} 3.767 / 2004$. Disponível em http://www.camara.gov.br/sileg/integras/257011.pdf. Acesso em 8 dez. 2007.

BRASIL. Constituição da República Federativa do Brasil: promulgada em 5 de outubro de 1988.

BRASIL. Lei $n^{\circ}$ 5.764, de 16 de dezembro de 1971.

IRION, João Eduardo. Cooperativismo e economia social. São Paulo: STS, 1997.

ORGANIZAÇÃO DAS COOPERATIVAS BRASILEIRAS (OCB). O cooperativismo no Brasil. Brasília: OCB, 1996.

. Apresentação - Cooperativismo brasileiro, 2007.

NORONHA, Adolfo Vasconcelos. Cooperativismo. [s.1.]: Cupolo, 1976.

ROSANVALlON, Pierre. La crisis del Estado Providencia. Madrid: Civitas, 1995.

ROSSI, Amélia do Carmo Sampaio. Cooperativismo à luz dos princípios constitucionais. Curitiba: Juruá, 2005.

SILVA, Emanuel Sampaio et all. Panorama do cooperativismo brasileiro: história, cenários e tendências. Revista UniRcoop, v.1 \#2, 2003. 